\title{
ANÁLISIS DEL IMPACTO EN EL TURISMO DE LA ESTRATEGIA DE DESARROLLO URBANO BASADA EN MEGAPROYECTOS. EL CASO DE LA CIUDAD DE VALENCIA*
}

\author{
Julia Salom Carrasco \\ María-Dolores Pitarch-Garrido \\ Universitat de València
}

\section{RESUMEN}

Desde finales de los años 80 del pasado siglo, las ciudades europeas están desarrollando políticas de gestión urbana en la línea de lo que se ha venido en denominar city-marketing, urban-branding, o urbanismo neoliberal. El objetivo de estas políticas es posicionar a la ciudad en el contexto internacional potenciando su singularidad, para lo cual la principal estrategia ha sido la construcción de mega-edificios y la organización de eventos con impacto en los medios de comunicación globales. El aumento de la atractividad turística en las ciudades es utilizado como un indicador de éxito de dichas políticas. La ciudad de Valencia no ha sido ajena a este tipo de estrategias. El presente artículo realiza un análisis de las consecuencias que la política urbana neoliberal ha tenido en el turismo de la ciudad de Valencia, en especial en lo que se refiere a su imagen de marca y a la vinculación del mismo con la oferta cultural de la ciudad.

Palabras clave: Megaproyectos, Urbanismo neoliberal, turismo cultural, Valencia.

Recibido: 17 de octubre de 2016

Devuelto para su revisión: 3 de febrero de 2017

Aceptado: 5 de abril de 2017.

Instituto Interuniversitario de Desarrollo Local. Universidad de Valencia. C/ Serpis, 29. 46022 VALENCIA (España).E-mail: julia.salom@uv.es, maria.pitarch@uv.es

* Este artículo se ha elaborado en el marco del proyecto «Sostenibilidad social, conectividad global y economía creativa como estrategias de desarrollo en el Área metropolitana de Valencia» (CSO2016-74888-C4-1-R), financiado por la Agencia Estatal de Investigación (AEI) y al Fondo Europeo de Desarrollo Regional (FEDER) dentro del Programa Estatal de Investigación, Desarrollo e Innovación Orientada a los Retos de la Sociedad, en el marco del Plan Estatal de Investigación Científica y Técnica y de Innovación 2013-2016, convocatoria de 2016. 


\title{
Analysis of the impact on tourism of the megaproject-based urban development strategy. The case of the city of Valencia
}

\begin{abstract}
Since the late 1980s, European cities have been developing urban management policies along the lines of what has come to be called city-marketing, urban-branding, or neoliberal urbanism. The aim of these policies is to position the city in the international context, enhancing its uniqueness, for which the main strategy has been the construction of megabuildings and the organization of events with an impact on the global media. The increase in tourist attractiveness in cities is used as an indicator of the success of these policies. The city of Valencia has not been foreign to this type of strategies. The present paper analyzes the consequences of neoliberal urban policy on tourism in the city of Valencia, especially as regards its brand image and its link with the city 's cultural offer.
\end{abstract}

Key words: Megaprojects, neoliberal planning, cultural tourism, Valencia.

\section{INTRODUCCIÓN}

Durante las últimas tres décadas -e incluso antes-, las ciudades de los países occidentales han crecido compitiendo. En cada una la ventaja o ventajas competitivas más destacadas se han potenciado y, si no había ninguna, se ha inventado. El objetivo era -y es- posicionar a la ciudad en la esfera internacional, aunque para ello se imiten iniciativas desarrolladas en otras ciudades o se hipoteque el futuro de sus residentes. Incluso, en ocasiones, tal posicionamiento, basado aparentemente en la innovación y la calidad, responde a intereses y criterios no claramente expresados.

Las ciudades son espacios de vida de la mayor parte de la población mundial, pero, además, son destinos turísticos cada vez más demandados (Cazer y Potier, 1996, McCanell, 2003, OCDE, 2009). Es por ello que las políticas de desarrollo urbano cuyos objetivos generales son la regeneración urbanística, el crecimiento económico y la confianza política, terminan materializándose en la capacidad de la ciudad para atraer turistas, es decir, aumentar su atractividad, lo cual, en caso de conseguirse, parece legitimar todo el proceso. Sin embargo, la creación y/o consolidación de un destino turístico de calidad, sostenible y socialmente responsable, es algo más complejo y no puede medirse únicamente con las cifras de llegada de turistas.

En España, el conocido como «efecto Guggenheim» se ha tratado de replicar en varias ciudades con mayor o menor éxito. Se trata de basar el proceso de regeneración urbana en la cultura como pivote y el turismo como resultado económico. Como indica Esteban (2007), «un ornamento como el Guggenheim debe tener la suficiente singularidad para atraer el turismo en una civilización transitada por la competencia entre imágenes.» (p. 53). Por lo tanto, una ciudad que aspira a ser destino turístico debe diferenciarse a través de una imagen destacada, innovadora, o mucho mejor, vanguardista, o no podrá ser competitiva. La cultura queda, en esta visión, relegada a un segundo plano. El efecto Guggenheim, por tanto, demuestra el potencial simbólico de la mega-arquitectura, a la 
que su infrautilización no le resta capacidad de atracción ni simbolismo. En esta línea, ciudades intermedias como Valencia (Ciudad de las Artes y las Ciencias), Zaragoza (Pabellón puente de Zaha Hadid), Sevilla (La Seta), Tenerife (Auditorio Adán Martín), Santiago de Compostela (A Cidade da Cultura), entre otras, han invertido una enorme cantidad de fondos públicos en la construcción de edificios emblemáticos y en la organización de eventos internacionales que pretendían servir como «logotipo» de la ciudad y mejorar su posicionamiento en el mercado turístico internacional. El éxito de dichas iniciativas ha sido muy cuestionado.

El objetivo de este artículo es analizar el impacto que sobre el turismo ha tenido la política basada en megaproyectos en la ciudad de Valencia, con el fin de valorar si ha sido adecuada para generar un desarrollo turístico integrado y sostenible a medio y largo plazo.

\section{LAS POLIÍTICAS URBANAS DE PROMOCIÓN EN LAS PRIMERAS DÉCA- DAS DEL SIGLO XXI Y EL DESARROLLO TURÍSTICO}

Estas iniciativas, desarrolladas sobre todo desde los años 80 del pasado siglo, han venido de la mano de una política urbana cuya idea central es que los gobiernos locales deben ser más innovadores y empresariales, centrándose en buscar nuevas vías para mejorar la economía. Este objetivo se alcanza bien mediante la intervención directa del gobierno en la puesta en marcha de nuevas empresas, o bien mediante la creación de un entorno que propicie el desarrollo de actividades económicas innovadoras con el fin de recuperar la competitividad perdida. Estas políticas constituyen la expresión urbana de la New Economic Policy, plataforma política del liberalismo conservador, que busca reorientar la intervención del Estado más allá de la regulación del mercado monopolístico, constituyéndose en instrumento para canalizar recursos públicos hacia la creación de infraestructuras sociales, físicas y geográficas que apoyen, financien, subsidien o promuevan nuevas formas de acumulación de capital. Es lo que Harvey (2012) denomina «urbanización del capital» y «rentas de monopolio», en referencia a que las características únicas e irrepetibles de un lugar aumentan su valor; o lo que Verdú (2003) califica de «capitalismo de ficción». Tras uno de producción y otro de consumo, el capitalismo actual no se conforma con que las empresas vendan, sino también deben gustar, se apela a lo emocional; y nada más íntimamente relacionado con la atractividad turística. En consecuencia, la renovación urbana se convierte en un objetivo intermedio, una precondición necesaria para la regeneración económica (Swyngedouw et al., 2002), a partir de un adecuado marketing de intangibles, de aspectos inmateriales, que facilita el tránsito de una política de infraestructuras a una imagen basada en los valores y en la cultura (Muñiz y Cervantes, 2010) y convierte a las ciudades en sí mismas en objetos de consumo (Mansvelt, 2008).

La política empresarial de promoción urbana (Harvey, 1989) va dirigida directamente a reposicionar la ciudad en un nuevo escenario, por lo que, en la búsqueda de nuevas especializaciones competitivas, destacan las estrategias relacionadas con la ciudad del conocimiento y la formación, la ciudad emprendedora, la ciudad del ocio y la calidad de vida, y la ciudad culta y creativa (Rausell, 2006, 2010). Los servicios culturales y crea- 
tivos se configuran como el elemento fundamental de competitividad urbana, lugares en los que se crea la narrativa que sostiene la economía cultural (Amin y Thrift, 2007, Méndez y Sánchez, 2011). La marca ciudad adquiere una dimensión social simbólica que se traduce en beneficio económico (Heredero y Chaves, 2015).

Este planteamiento conduce a resaltar la importancia de re-imaginar y recrear el espacio urbano, no sólo a los ojos de los planificadores y residentes, sino principalmente cara al extranjero, el inversor, el hombre de negocios o turista adinerado. Así pues, las estrategias no son únicamente económicas, sino que se orientan también hacia la gestión de la dimensión simbólica y la construcción de identidades. Por tanto, los grandes proyectos emblemáticos, la promoción de eventos con gran proyección mediática (Marchena, 1998, San Eugenio, 2013, Fernández Alles, 2014, Gago et al., 2017) y el place-marketing constituyen una herramienta fundamental para atraer capital de inversión y mejorar la vitalidad urbana. De esta forma, el city-marketing y el brand management entran en la política local, y los procesos de espectacularización vinculados a los eventos y grandes proyectos contribuyen a la creación de dicha marca urbana. Existe un claro paralelismo entre la gestión de una marca corporativa y la propia marca de la ciudad (Heredero y Chaves, 2015). En definitiva, como señalan Brenner et al (2010), el objetivo de la planificación urbana neoliberal es lograr unas condiciones territoriales que favorezcan la economía de mercado, y, para ello, lo local, la ciudad, juega un papel fundamental en cuanto que interioriza y prioriza los discursos y acciones de este tipo de política. La política urbana neoliberal es un ejemplo claro de lo que Peck y Theodore (2015) denominan fast policy, en referencia a las ideas políticas que son capaces de generar un impacto a nivel mundial en relativamente poco tiempo. El turismo, como generador de experiencias y gestor de lo intangible, no sólo no es ajeno a esta realidad, sino que se constituye, casi sin quererlo, en el centro de la misma.

Esta política urbana descrita anteriormente no se orienta estrictamente al desarrollo turístico de la ciudad. Se trata de poner en marcha una estrategia para el posicionamiento internacional de las ciudades en un entorno competitivo en el que consideran necesario destacar. El turismo es considerado una consecuencia positiva del desarrollo de dicha política en cuanto que genera empleo y beneficio económico a nivel local, al mismo tiempo que contribuye a la definición y difusión de la imagen internacional de la ciudad. Sin embargo, las buenas cifras en lo que respecta a la creación de negocios turísticos, fundamentalmente de alojamiento y de restauración, hacen olvidar temas controvertidos como la calidad del empleo, los salarios, la calidad del servicio, los problemas relacionados con la superación de la capacidad de carga, con la ineficaz accesibilidad a los recursos turísticos, etc. Tampoco se cuestiona el papel de la administración pública y la participación ciudadana, que para muchos expertos es clave en cualquier proceso de planificación urbana (Monfort, 2000, UNESCO, 2006, OCDE, 2009). El número de visitantes y el gasto son los dos elementos que se utilizan para medir el éxito de un destino turístico; por tanto, es necesario seguir creciendo. Para ello, las ciudades necesitan desarrollar la oferta, ser únicas y promocionarse como tales.

De cualquier forma, la relación más inmediata entre turismo y política urbana neoliberal es a través del llamado turismo cultural. Los beneficios de este tipo de segmento turístico son bien conocidos (Richard y Musters, 2010, OCDE, 2009), y entre ellos destaca 
su capacidad para proyectar la imagen externa de la ciudad, atraer inversiones y generar beneficios para la comunidad local. Sin embargo, y en consonancia con las políticas urbanas antes expuestas, algunas ciudades han desarrollado una oferta cultural relacionada con la comercialización de la propia ciudad y, como indican Queiroz y Rastrollo-Horrillo (2012), «cuando la lógica del turismo se sobrepone a la cultura, vender "cultura" puede no ser fácil» (p. 110).

La utilización de la cultura para justificar inversiones extraordinarias es habitual, y a ello se suma la argumentación de tipo turístico, que, basada en el atractivo cultural, promete oleadas de visitantes como respuesta a la venta de la ciudad y a la generación de una imagen suficientemente atractiva. Todo se encuentra claramente interrelacionado dentro del discurso neoliberal, pues, para que un recurso se convierta en un producto turístico, se necesita, sobre todo, calidad e imagen, y ambas cosas se dan, con profusión, en la ciudad neoliberal. El resultado en algunas partes del mundo es que el número de proyectos denominados culturales está creciendo más rápidamente que la demanda turística, pues la creación, -que no recreación (basada en los recursos más tradicionales)-, de una oferta cultural asociada a nuevos espacios, megaarquitectura, macroeventos, etc., no ha hecho sino mermar la capacidad de diferenciación de las ciudades, pues lo nuevo es emulable por la facilidad para ser copiado (Momfort, 2010). Se trata de la McDonalisation de los espacios (Ritzer, 1983), es decir, la disminución de su singularidad y autenticidad, producto de la homogeneización de un mundo global.

A pesar de que este riesgo existe, el flujo turístico hacia estos lugares, iconos de la modernidad, es destacable, y aunque los turistas tienen sus propias motivaciones, la imagen de lugares extraordinarios sigue siendo un potente atractivo (Urry, 2002, Richards, 2002). Hernández y Torres (2015) denominan a estos espacios los glolugares, es decir, urbes insertas en la red de ciudades globales, con una imagen novedosa (aunque repetida), cosmopolita y vanguardista, en la que lo local o tradicional ha perdido valor, quedando como un complemento «pintoresco» de la nueva realidad que se transmite al mundo. El turismo es el componente cultural de la globalización (McCanell, 2003), y, por tanto, el turismo cultural resulta de gran relevancia en el entorno urbano renovado (al menos en imagen), pues no podemos olvidar que una de las motivaciones de los turistas que visitan ciudades es, desde el comienzo de la propia actividad turística, la regeneración del paisaje urbano, de su imagen y atractivo (Cazer y Potier, 1996). La ciudad se convierte en un contenedor donde se desarrollan las propuestas culturales, y es tan importante el contenedor como el propio contenido, si no más. Esta realidad ha generado críticas por la falta de consideración hacia otro tipo de expresiones culturales que no estén asociadas a la política de marca, al alejamiento de los intereses locales y, sobre todo, por el coste que conllevan. Sin embargo, la aplicación de una lógica de branding a las ciudades se ha hecho, en gran parte, desde una visión de la ciudad como destino turístico, de espaldas a las iniciativas y demandas de los ciudadanos.

Por último, la New Urban Policy ha tenido algunas consecuencias sociales y en términos de gobernanza que cabe señalar. Swyngedouw et al. (2002), apuntan que la mayor parte de estos proyectos han sido decididamente liderados por el sector público, y a menudo financiados por él. Los riesgos son asumidos por el Estado, en ocasiones compartidos con el sector privado, por lo que, dado que por la naturaleza de los proyectos 
éstos suelen incurrir en déficit, es frecuente que se produzca la socialización del coste y el riesgo, así como la privatización de los posibles beneficios. Además, los proyectos se presentan como una alternativa viable que combina las ventajas de la flexibilidad y las acciones dirigidas a un objetivo con una tremenda capacidad simbólica. El proyecto emblemático captura un segmento de la ciudad y lo convierte en el símbolo de una nueva reestructurada y revitalizada metrópolis en una poderosa imagen de innovación, creatividad y éxito, pero sus efectos sobre el conjunto de la ciudad no son claros, pues están poco integrados en el proceso urbano general, acentúan la polarización social a través del funcionamiento de los mercados inmobiliarios y se producen cambios en las prioridades del gasto público -desde los objetivos sociales a las inversiones en el entorno construido-, todo lo cual consolida una ciudad esencialmente fragmentada. El turismo contribuye poderosamente a consolidar esta segmentación, al centrarse únicamente en la «ciudad externa», definida por estereotipos que el turista espera consumir (destination brands), mientras que la "ciudad interna" (place brand) es la que perciben los residentes, la del día a día (Heredero y Chaves, 2015).

A continuación, analizamos la implementación de las políticas urbanas basadas en el brand management y el city marketing en la ciudad de Valencia, como paradigma de política neoliberal entre los años 1995 y 2015.

\section{LA POLÍTICA URBANA EN LA CIUDAD DE VALENCIA (1995-2015). LOS MEGAPROYECTOS: ARQUITECTURA Y EVENTOS}

Desde principios de los años 90 del siglo XX, y siguiendo la estela comenzada en el año 1992 por las ciudades de Barcelona, con la celebración de los Juegos Olímpicos, y Sevilla, con la organización de la Exposición Universal, muchas ciudades españolas han apostado por la pareja grandes proyectos-grandes eventos. Hasta la crisis financiera e inmobiliaria de 2008, la combinación de ambas se entendió como una muestra de modernidad y visibilidad internacional. La ciudad de Valencia no fue ajena a este tipo de iniciativas, bien al contrario, en el contexto español, ya de por sí inflacionario, es un buen ejemplo, si no el mejor, de grandiosidad y despilfarro.

Como ha ocurrido en otras ciudades españolas (Barcelona, Bilbao, Madrid, etc.), Valencia ha experimentado desde mediados del siglo XX un modelo de crecimiento urbano en el que los negocios inmobiliarios han sido el elemento motor de la actividad económica, favorecidos por los significativos cambios en la legislación urbanística estatal y regional que han facilitado la generación de una urbanización intensa y dispersa, así como grandes desarrollos residenciales. A ello se ha unido una importante inversión pública en megaeventos, grandes proyectos e inmensas infraestructuras, como producto del llamado «entrepreneurial urbanism», basado en sólidas coaliciones entre las sociedades financieras, los promotores de suelo y las autoridades locales y regionales (Romero et al., 2016).

La vía seguida por la ciudad de Valencia presenta algunos rasgos distintivos en relación con la de otras ciudades españolas (Cucó, 2013), entre los que destacan, por ejemplo, que, a diferencia de Madrid, su agenda urbana no se centró en una intensiva urbanización del Área Metropolitana, sino que se focalizó en grandes desarrollos inmobiliarios, la organiza- 
ción de mega-eventos y la inversión en grandes proyectos urbanos. A diferencia de Bilbao y Barcelona, Valencia otorga mayor preferencia a las políticas económicas, mientras que en Barcelona y Bilbao se observa un mayor equilibrio entre estas políticas y las de base social, medioambiental y urbanística. Otro rasgo diferencial del caso valenciano es la continuada falta de consenso entre el gobierno municipal y el resto de instancias políticas y ciudadanas, así como un liderazgo público ejercido casi en solitario.

El urbanismo democrático en la ciudad de Valencia supuso la aprobación del Plan General de Ordenación Urbana en 1988. Este plan, basado en la ideología del crecimiento, facilitó el desarrollo de algunas actuaciones de gran relevancia que contribuyeron a mejorar la calidad urbanística de la ciudad, entre las que destacan el Jardín del Turia, El Paseo Marítimo, la rehabilitación del centro histórico, el Parque de Cabecera, las nuevas avenidas periféricas, como la de Tarongers (con el nuevo campus universitario), la avenida de Francia y el Bulevard Sud, la red de Metro-Valencia (metro y tranvía), el Parque Central (en construcción), Sociópolis, La Zona de Actividades Logísticas del Puerto (ZAL), el IVAM (Museo de Arte Contemporáneo), el Palau de la Música, el Palau de Congresos, etc. Sin embargo, el claro proceso de desarrollo urbanístico vinculado a la política neoliberal se evidencia a finales de la década de los 80 , pero sobre todo en los años 1990, con un gobierno regional y municipal de perfil conservador que van a tener como objetivo dar una nueva imagen internacional de la ciudad a partir de grandes construcciones emblemáticas y la organización de importantes acontecimientos deportivos y sociales a nivel internacional. Para algunos, este proceso ha convertido a la ciudad de Valencia en una «metrópoli clónica glocalizada» (Santamaría y Moncusí, 2013) que en poco se diferencia de otros destinos-producto turísticos que buscan atraer un turismo cultural y de ocio en el que el número importa más que la calidad.

El año 1989 marca el inicio, cuando el gobierno regional, del partido socialista, toma la iniciativa para la construcción de un complejo científico-cultural que terminará tomando el nombre de Ciudad de las Artes y las Ciencias (CAC), localizado en el antiguo cauce del río Turia (desviado por el sur de la ciudad tras la riada de 1957) y entendido como parte de la rehabilitación urbanística de toda una antigua zona industrial abandonada hacia el puerto, en un intento de iniciar una política de rehabilitación del tipo que se había llevado en otras ciudades europeas siguiendo el modelo del waterfront a partir de complejas operaciones de renovación urbana.

En 1991 se aprueba el proyecto presentado por el arquitecto Santiago Calatrava después de algunos cambios respecto al diseño original, vinculados en gran parte al cambio de gobierno regional. Tres años después se inician las obras (operación muy beneficiosa para las empresas constructoras, pero no tanto, como se verá, para el erario público). En 1998 se inaugura el complejo (aún sin terminar) con la apertura de uno de sus edificios emblemáticos: L'Hemisfèric, un cine IMAX y 3D con una pantalla cóncava de 900 metros cuadrados. En el año 2000 se inauguró el Museo de las Ciencias Príncipe Felipe y el Umbracle, un paseo ajardinado o mirador. El origen de la idea fue el museo de las ciencias, en gran medida pensado para la atracción turística, pero el proyecto se volvió faraónico en pocos años, a pesar de que no se ejecutará completo. En diciembre de 2002 se inauguró L'Oceanogràfic, publicitado como el mayor acuario de Europa y diseñado por el arquitecto Félix Candela. En octubre de 2005 abrió sus puertas el Pala- 
cio de las Artes Reina Sofía, un teatro de la ópera que es hoy el emblema del proyecto de Calatrava. En el 2007 el complejo del CAC ganó el concurso de los 12 Tesoros de España, el único en la Comunidad Valenciana y el único contemporáneo junto al museo Guggenheim de Bilbao. El coste total del primer proyecto ascendía a unos 150 millones de euros, mientras que el coste real ha multiplicado por cuatro ese presupuesto. El último icono de la CAC es el Ágora, un espacio concebido como una gran plaza abierta para la organización de eventos. En 2009 acogió el primer torneo de Valencia Open 500 de Tenis, y desde entonces ha estado abandonado y sin terminar. En breve será la sede de Caixa Forum, la fundación cultural de Bancaixa que buscaba en Valencia un edificio simbólico y ha llegado a un acuerdo con el consistorio y la Generalitat.

En paralelo prolifera la organización de grandes eventos, con una clara subestimación de la demanda, pero con la justificación de su gran capacidad de atraer turistas y generar gasto en la ciudad. Los eventos son vistos como una oportunidad para los destinos turísticos que buscan aumentar su atractivo y visibilizarse a nivel nacional, pero, sobre todo, internacional. En el año 2003 se hizo público que Valencia acogería la principal competición náutica del mundo: la Copa América. Se celebró dos veces: en 2007 y en 2010. Según los organizadores fue un éxito de público y participantes. Lo cuantificable es que disparó las cifras de turistas extranjeros en la ciudad. Sin embargo, tras el evento, la mayoría de sus infraestructuras quedaron sin uso y en la actualidad la Marina Real, donde se localizaron las actividades más emblemáticas, todavía es objeto de un proceso de reflexión -y planificación- para diseñar un uso urbano de esta zona.

Por otra parte, la ciudad de Valencia construyó en la Marina un circuito de Fórmula 1, con el fin de celebrar la Copa del Mundo, entre otras. Se celebró el Gran Premio de Europa entre 2008 y 2012. Sin embargo, el contrato tuvo que cancelarse porque la prueba no era rentable. El elevado canon que la ciudad debía pagar por la celebración de la prueba, la propia construcción del circuito, los derechos de televisión y la compra de Valmor (empresa que se constituyó para la promoción y organización del Gran Premio de Fórmula 1 en Valencia) por un precio simbólico de 99 céntimos, superó los 33 millones de euros; la operación, además, está enturbiada por varios delitos de corrupción.

El modelo urbano de Valencia, ligado a su imagen como ciudad de negocios y turismo, ha consumido la potencialidad cultural de la ciudad, dada la enorme identidad que relaciona estos elementos (mega-arquitectura y mega-eventos) con su imagen, ensombreciendo cualquier otro evento cultural o patrimonial a nivel local. La identificación de la arquitectura de marketing forma parte de las actuaciones ligadas a la promoción externa de Valencia, lo cual ha supuesto una desconexión con las prácticas culturales de la mayoría de la población residente, que se identifican poco con dichos elementos, vinculados para el imaginario popular a casos de corrupción y despilfarro. La administración regional, en connivencia con la local, ha priorizado las acciones para la promoción internacional de la ciudad y han descuidado los referentes locales, aunque éstos no han dejado de desarrollarse buscando formas alternativas de promoción y gestión (Hernández y Torres, 2015). La política urbanística neoliberal ha conseguido atraer a un «turismo de contenedores» (arquitectura espectacular pero vacía de contenido) que ha hipotecado, en parte, el futuro de sus residentes. 


\section{EVOLUCIÓN DEL TURISMO EN VALENCIA. DEL TURISMO DE REUNIO- NES AL TURISMO DE ESPECTÁCULO}

\subsection{La imagen}

En relación con lo anteriormente expuesto, cabe recordar que tradicionalmente la ciudad de Valencia se ha promocionado desde las instituciones a través de sus fiestas y eventos, los cuales se han constituido en iconos de la ciudad (por ejemplo, la Exposición Regional Valenciana de 1909, o las Fallas, recientemente declaradas Patrimonio de la Humanidad por la UNESCO). Sin embargo, la imagen de marca basada en la CAC, es, como indican Puche y Obiol (2011), «ajena a la autenticidad valenciana» (p. 193), lo que hace que la ciudad siga careciendo de una marca genuina y asumida como reflejo de su identidad. La promoción turística de la ciudad de Valencia como ciudad-espectáculo confunde a los turistas y los residentes se debaten entre la valoración positiva de la oferta artístico-cultural y la crítica a una fórmula de desarrollo en la que se socializan las pérdidas y se privatizan los beneficios (Santamaría y Moncusí, 2013). El turismo es un creador potente de marca o imagen, por lo que con el tiempo es posible que, como ha ocurrido en otros destinos, sean los habitantes de la ciudad los que se identifiquen con esa imagen de modernidad, cosa que ya parece estar ocurriendo por cuanto la imagen de la CAC es elegida en 2004 por el $18 \%$ de los ciudadanos como símbolo de la ciudad frente al $21 \%$ que eligen el emblema tradicional del Micalet, la torre de la catedral (Boira, 2005, cit. en Puche y Obiol, 2011).

Está claro que la imagen de marca de una ciudad pretende apropiarse de ventajas comparativas con otros destinos, que en el caso del turismo supone un «desplazamiento emocional» (Puche y Obiol, 2011) previo al viaje y le ofrece una singularidad excepcional que motiva el viaje. La construcción del imaginario turístico se sobrepone, en ocasiones, a la ciudad percibida por sus habitantes para acabar suplantándola, a pesar de haber sido una imagen creada para el visitante. No deja de ser cierto que esa imagen define de alguna manera la identidad y el afecto sobre un lugar, así como sus aspiraciones, pero al ser parte de un proceso de venta (marketing urbano) se ajusta más a las expectativas de los compradores (en este caso turistas) que a la esencia del territorio. En la ciudad de Valencia se creó el Centro de Estrategias y Desarrollo de Valencia, entidad público-privada presidida por el Ayuntamiento, hoy extinguida, cuyo objetivo explícito era mejorar la imagen internacional de la ciudad y atraer turismo. Las manifestaciones en torno a ideas como la revitalización, el crecimiento y la renovación han formado parte de los discursos orientados a hacer de Valencia una ciudad internacional y espectacular (Santamaría y Moncusí, 2013). La espectacularización en el caso de Valencia ha sido señalada y estudiada por autores como Boira (2010), Rausell (2010), Gaja (2016) y Sorribes (2016).

Incluso los residentes en Valencia reconocen claramente los cambios que ha experimentado la ciudad, en especial en dos sentidos; ambos explican el aumento del turismo. Estos cambios son, por un lado, el posicionamiento de la ciudad en el mercado turístico internacional con un sello de excelencia (asociado al urbanismo de autor y a los eventos distintivos), y, por otro lado, la diferenciación de Valencia respecto a otras ciudades intermedias con las que compite (Bilbao, Zaragoza, Sevilla, etc.) (Santamaría y Moncusí, 2013). 


\subsection{Las cifras}

En los últimos 20 años, la ciudad de Valencia ha cambiado su modelo turístico (Rausell, 2010). El número de turistas ha crecido espectacularmente y se ha abierto a nuevos segmentos de demanda, como es el turismo de cruceros. Además de la transformación de la imagen de la ciudad, hay que considerar también la mejora de la conectividad (vuelos baratos -Ryanair- y AVE), así como el turismo Erasmus, la organización de ferias, congresos, etc.

\subsubsection{Número de viajeros y gasto}

El número de viajeros llegados a la ciudad de Valencia ha pasado de 372.000 en 1992 a 1.867.000 en 2015. A pesar del estancamiento durante los primeros años de la crisis (2007 a 2012), en los que la cifra de turistas se mantuvo alrededor de 1.800 .000 (el peor año fue 2010 con 1.500.000 viajeros), el total no ha dejado de crecer, aunque de forma más moderada en el último periodo (2012-2015) (gráfica 1).

\section{Gráfica 1 \\ EVOLUCIÓN DEL NÚMERO DE VIAJEROS Y PERNOCTACIONES EN LA CIUDAD DE VALENCIA (1992-2015)}

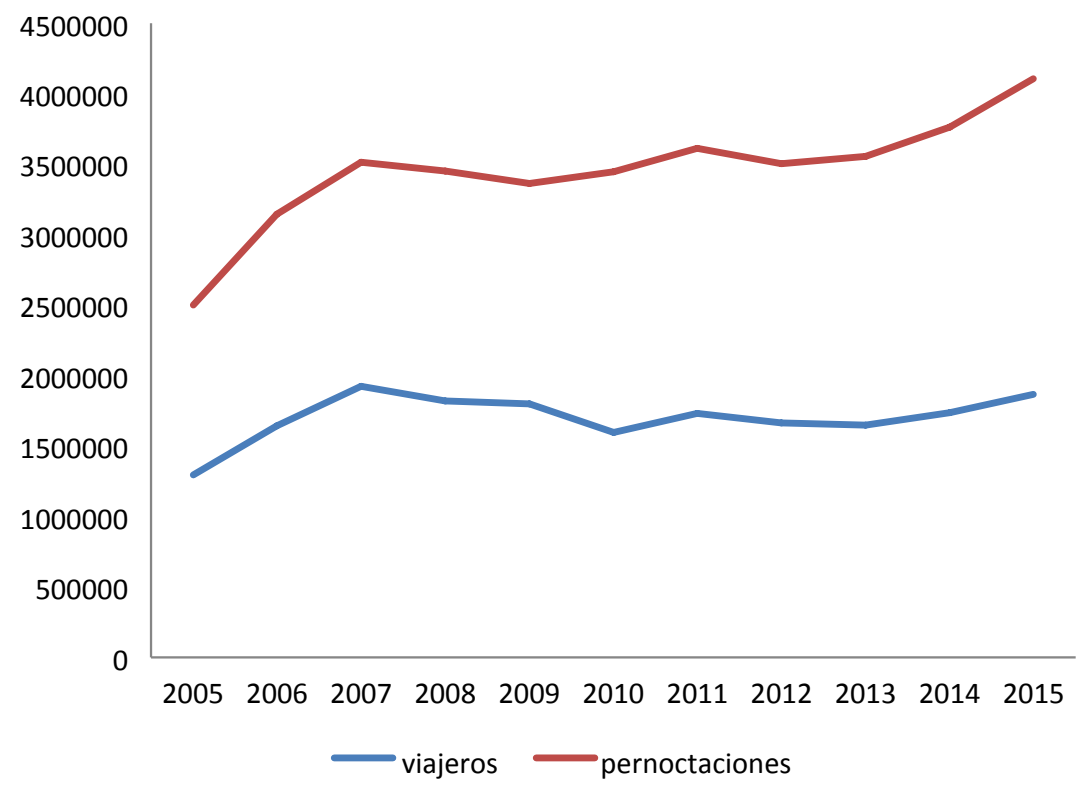

Fuente: INE.

En la actualidad (datos de 2015), la ciudad de Valencia concentra un 28,5\% de los viajes y un $22,2 \%$ de las pernoctaciones de la provincia, habiendo duplicado sus plazas de alojamiento en hoteles entre 2000 y 2007. El gasto total de los turistas en la ciudad es de unos 
340 millones de euros anuales, manteniéndose respecto a años anteriores, a pesar de que ha disminuido ligeramente el número de viajeros (-17,8\% respecto a 2015), lo que significa que crece el gasto por viaje $(21,7 \%)$ y la estancia media $(5,8 \%)$. Las tarifas del alojamiento han crecido un 3\% respecto a 2015, por lo que la rentabilidad también lo ha hecho (en un 9,6\%).

\section{Gráfica 2 \\ PROCEDENCIA DE LOS TURISTAS EN LA CIUDAD DE VALENCIA}

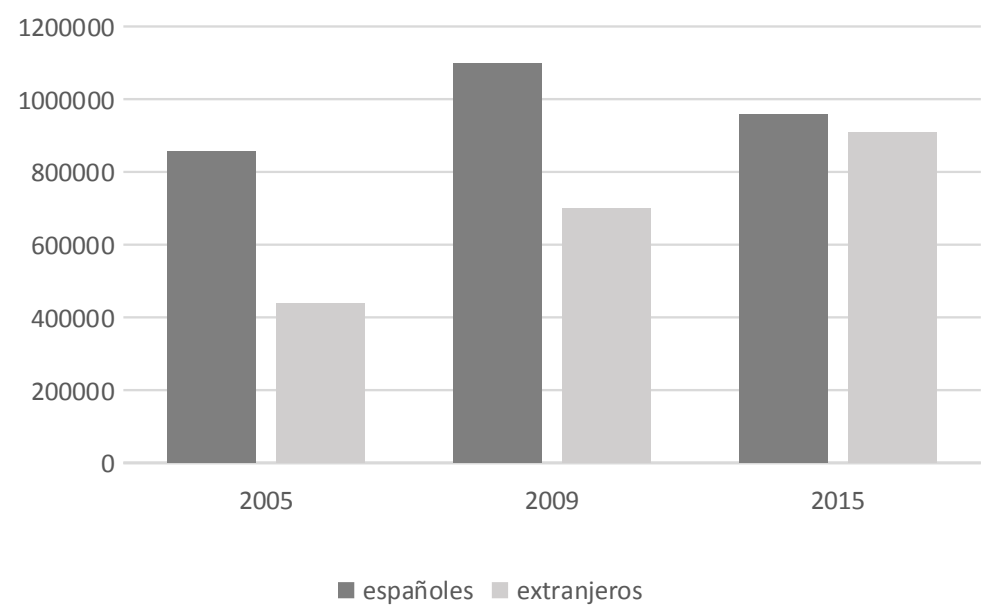

Fuente: INE.

La mayor parte de los turistas son españoles, pero los que más han crecido son los extranjeros, que entre 2005 y 2015 doblan su número (gráfica 2). Los de procedencia nacional apenas experimentan variación entre ambas fechas, aunque aumentan en la etapa más dura de la crisis, durante la cual los viajes de los españoles al extranjero disminuyen considerablemente, aumentando la demanda de destinos nacionales, entre los que Valencia se encuentra bien posicionada.

\subsubsection{Equipamiento turístico}

La ciudad ha experimentado un claro cambio en lo que se refiere a equipamiento turístico, en particular alojamiento y restauración. En el primer caso, Valencia ha pasado de 7.200 plazas hoteleras en 1996 a más de 16.000 en 2016, aumentando de forma continuada hasta 2007, fecha en que la oferta hotelera se estanca, con cierre de algunos hoteles, hasta la actualidad. El número de hostales experimenta escasa variación pasando de 756 plazas en 1997 a 764, incluso disminuye ligeramente entre los años 2006 y 2008 (apenas algo más de 500 plazas). La apuesta del empresariado turístico ha sido claramente por los hoteles, en particular los de categoría alta, en línea con la imagen megalómana de la ciudad, pero con dificultades reales para ser rentables, por lo que algunos han tenido que cerrar o transformarse hacia categorías inferiores. En 2010 los hoteles de 5 estrellas suponían el 17\% de las 
plazas hoteleras de la ciudad (por encima de la media de la provincia que se situaba en el 8\%), mientras que en 2016 esta cifra es del 9,6\% (en la provincia es del 4,6\%). Sin embargo, los hoteles de 4 estrellas aumentan su oferta de plazas, suponiendo en el año 2010 el $53 \%$ y en el 2016 el 60\% del total de plazas hoteleras ofertadas en la ciudad (Gráfica 4).

\section{Gráfica 3 \\ EVOLUCIÓN DEL NÚMERO DE PLAZAS EN HOTELES \\ Y HOSTALES EN LA CIUDAD DE VALENCIA}

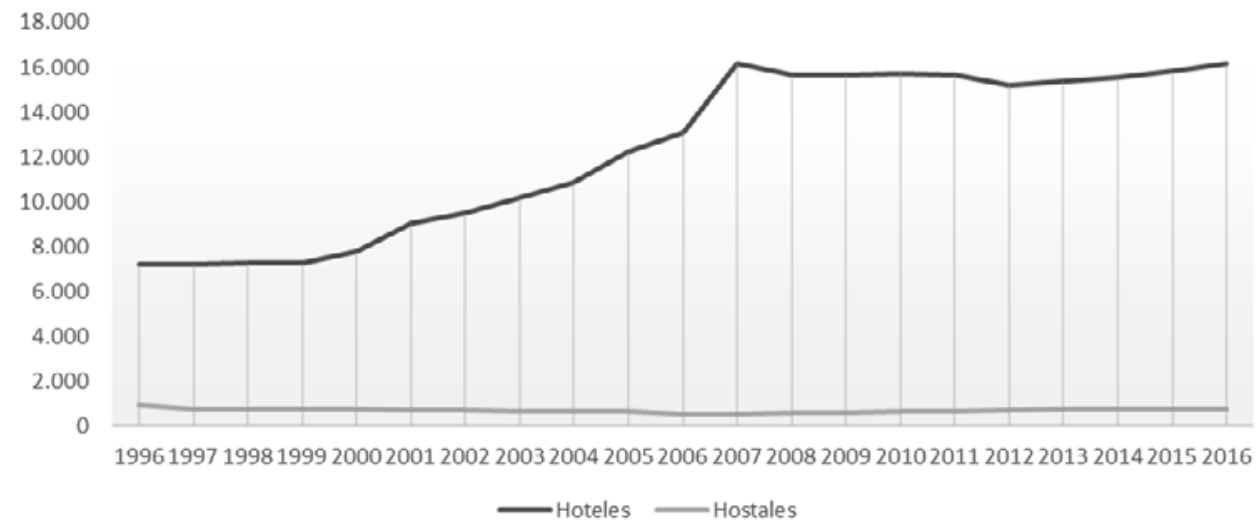

Fuente: Agencia Valenciana del Turismo.

\section{Gráfica 4 \\ PLAZAS HOTELERAS SEGÚN CATEGORÍA \\ EN LA CIUDAD DE VALENCIA (2000-2016)}

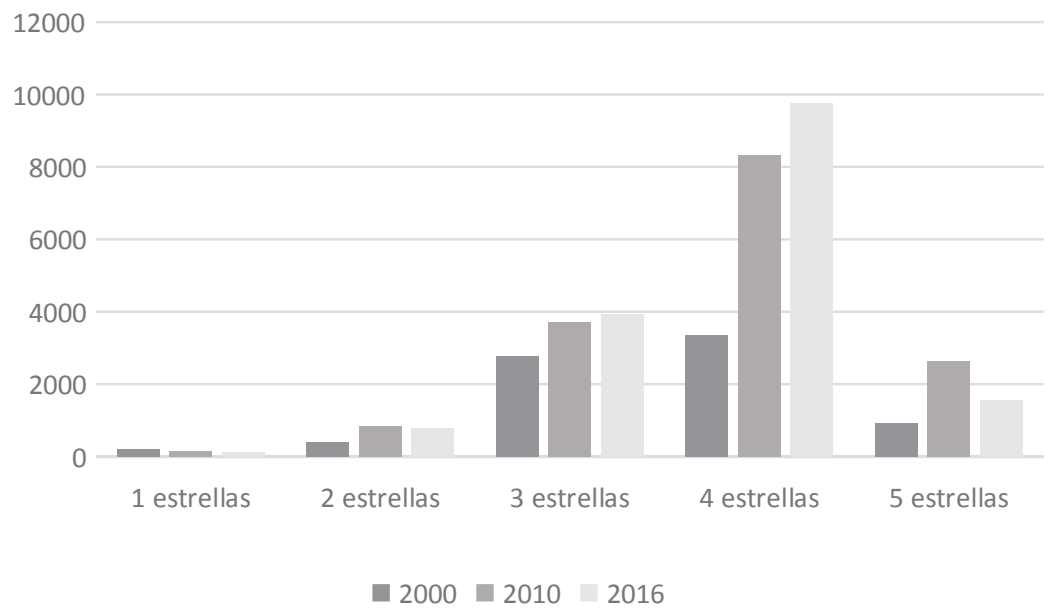

Fuente: Agencia Valenciana del Turismo. 
La oferta de alojamiento extrahotelero se ha disparado en el sector de los apartamentos turísticos, con dos puntos de inflexión, los años 2007 y 2015 (Gráfica 5). La crisis económica puede explicar en gran parte la puesta en alquiler turístico de pisos que ofrecen un precio más económico si se viaja en familia o grupo. Desde 2015 la necesidad legal de que aflore este tipo de oferta (las multas son cuantiosas y las inspecciones frecuentes) ha aumentado el número de las mismas considerablemente, lo que hace pensar que en los años anteriores había una oferta no legalizada que funcionaba a través de plataformas on line sobre todo.

\section{Gráfica 5 \\ EVOLUCIÓN DEL NÚMERO DE APARTAMENTOS TURÍSTICOS EN LA CIUDAD DE VALENCIA}

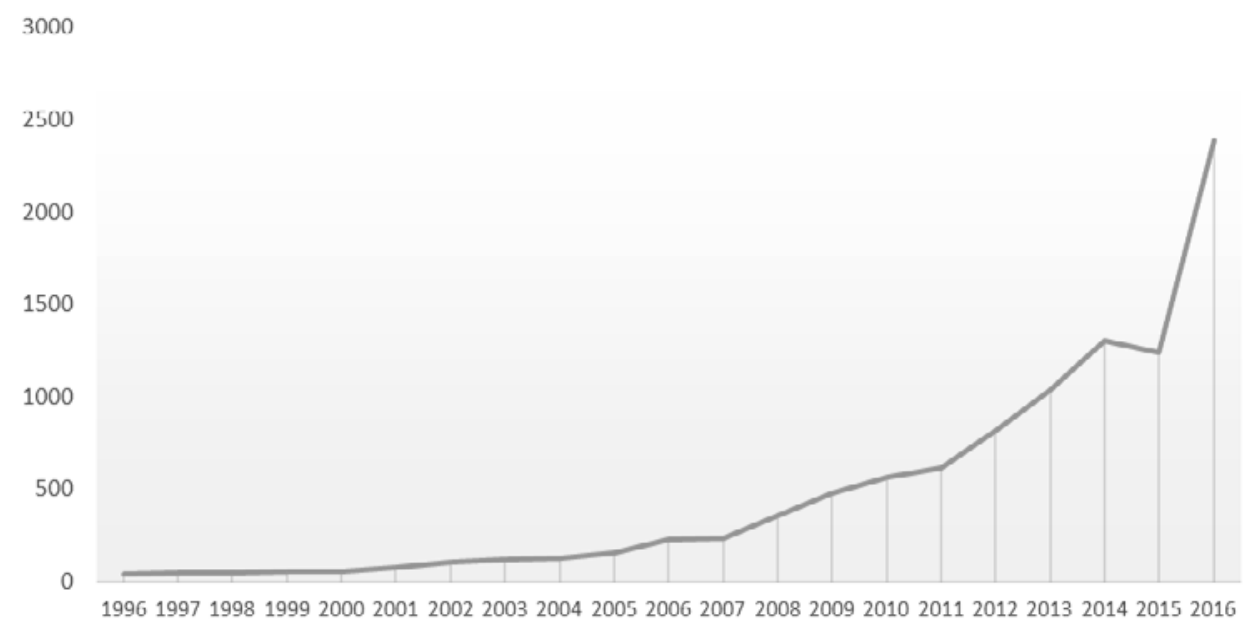

Fuente: Agencia Valenciana del Turismo.

El equipamiento relacionado con la restauración ha experimentado una evolución paralela a la de los alojamientos (Gráfica 6). Sólo el año 2003 supuso una ligera reducción del número de restaurantes en Valencia, sin embargo, entre 2010 y 2011 se produjo un aumento para estabilizarse a partir de 2012. Valga como ejemplo la cifra de 42.600 plazas de restaurante en 1986, y 128.400 en 2016, lo que supone un crecimiento de más del $300 \%$.

El aeropuerto de Valencia es una de las infraestructuras turísticas clave. De hecho, a su ampliación se debe, entre otras causas, el posicionamiento de la ciudad como puerto base para las compañías navieras españolas más importantes. La competencia del AVE ha mermado la capacidad del aeropuerto como infraestructura de recepción de turismo, en especial del turismo nacional (tabla 1). El número de pasajeros registrados en la última década ha aumentado ligeramente, pero ha vuelto a descender desde 2008 hacia una cierta estabilización. 


\section{Gráfica 6 \\ EVOLUCIÓN DEL NÚMERO DE RESTAURANTES \\ EN LA CIUDAD DE VALENCIA}

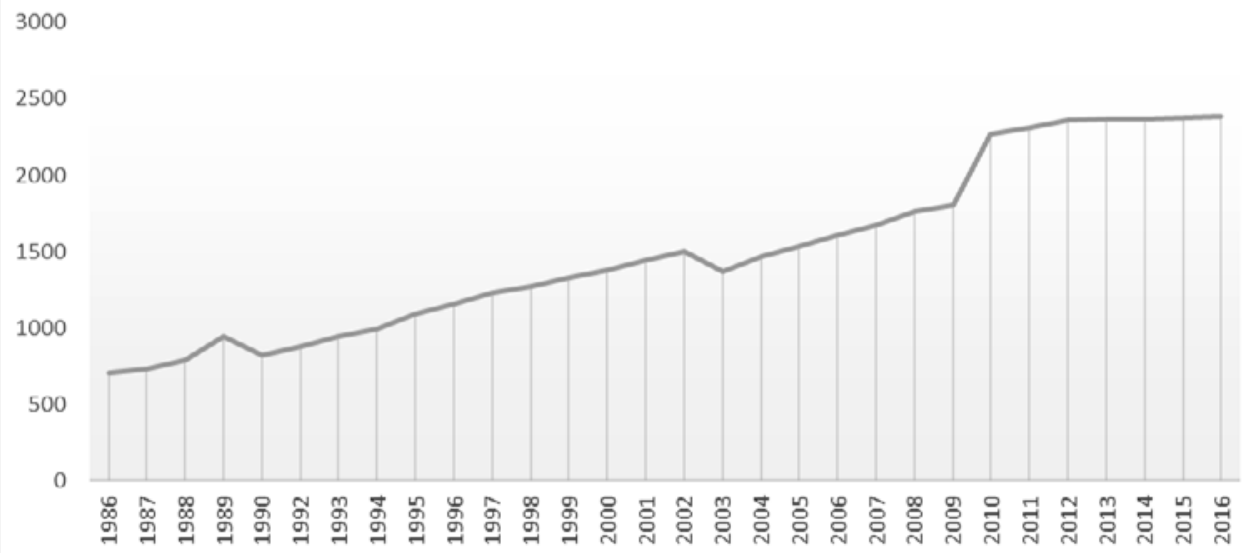

Fuente: Agencia Valenciana del Turismo.

Tabla 1

EVOLUCIÓN DE LA LLEGADA DE PASAJEROS

AL AEROPUERTO DE VALENCIA

\begin{tabular}{|c|c|}
\hline Año & Número de pasajeros \\
\hline 2005 & 2.312 .851 \\
\hline 2006 & 2.479 .719 \\
\hline 2007 & 2.953 .305 \\
\hline 2008 & 2.897 .131 \\
\hline 2009 & 2.369 .333 \\
\hline 2015 & 2.521 .720 \\
\hline
\end{tabular}

Fuente: AENA.

\subsubsection{Nuevos segmentos de demanda}

En cuanto a la demanda, como se ha señalado, Valencia ha diversificado sus segmentos de mercado, destacando, por lo novedoso y por su gran crecimiento, el turismo de cruceros. Su importancia está relacionada con el posicionamiento de la ciudad en los mercados internacionales a partir de la difusión de la imagen de la CAC (Sanz y Zhelyazkova, 2014). El número de cruceristas se ha multiplicado por tres en la última década y su presencia en la ciudad se ha hecho mucho más evidente (tabla 2). Este tipo de turismo ha sido promovido por las entidades públicas (Plan Estratégico de Turismo 2012- 2015, realizado por la Turismo Valencia y Plan Director de Cruceros 2011, de la Autoridad Portuaria de Valencia), mejorando las infraestructuras del puerto y su posicionamiento como 
puerto base ( 5 compañías usan el puerto como base), pero al mismo tiempo se ha podido aprovechar algunos factores ajenos como la congestión del tráfico de cruceros en algunos puertos europeos como Barcelona, Palma de Mallorca o Livorno.

\section{Tabla 2}

EVOLUCIÓN DEL TURISMO DE CRUCEROS EN LA CIUDAD DE VALENCIA

\begin{tabular}{|l|c|c|c|c|c|c|}
\hline & 2005 & 2006 & 2007 & 2008 & 2009 & 2015 \\
\hline $\mathrm{N}^{\circ}$ de cruceros & 110 & 80 & 155 & 164 & 143 & 174 \\
\hline $\mathrm{N}^{\circ}$ de pasajeros & 106.724 & 86.774 & 179.209 & 199.335 & 184.909 & 371.374 \\
\hline Número de pasajeros medio por crucero & 970 & 1.085 & 1.156 & 1.215 & 1.293 & 2.134 \\
\hline
\end{tabular}

Fuente. Autoridad Portuaria del Puerto de Valencia.

La llegada de cruceros no significa el desembarque de sus pasajeros. En 2012 sólo desembarcaban en Valencia el 25\% de los pasajeros, mientras que en 2009 lo hizo el 50\%. A pesar de la aparente reducción, el número total de visitantes en la ciudad procedentes de los cruceros sigue aumentando (Sanz y Zhelyazkova, 2014). Según Turismo Valencia, el impacto económico, suponiendo un gasto medio entre 62 y 80 euros diarios, se ha calculado en más de 45 millones de euros anuales (2016). El número de escalas también ha aumentado. El primer hito en este sentido tuvo lugar en 2002 con la inauguración de la terminal de pasajeros de Acciona Transmediterránea. El segundo en 2007, con la celebración de la Copa América.

Según un informe realizado por la Cámara de Comercio y la Agencia Valenciana de Turismo $^{1}$, el puerto de Valencia es el que cuenta con más tráfico de cruceros de la Comunidad Valenciana (cuota del 82\%) y el $7^{\circ}$ de España. En 2015 recibió 172 buques y 371.374 visitas de cruceristas, cantidad inferior a 2014 y todavía lejana del máximo alcanzado en 2012 (480.233 cruceristas). El número de turistas procedentes de la llegada de cruceros parece estar estabilizándose, aunque las previsiones de ampliación del puerto pudieran truncar esta tendencia y continuar su aumento hacia cifras que ya se encuentran cerca de superar la capacidad de carga de la ciudad.

En cuanto a la valoración de la ciudad por parte de los cruceristas que desembarcan para conocerla, cabe señalar que, según datos de la Cámara de Comercio, la mayoría manifiesta una elevada satisfacción con la ciudad, el $70 \%$ indica que tras su visita, la imagen percibida es mejor de la esperada y el $95 \%$ recomendará Valencia a familiares y amigos. El $90 \%$ manifiesta su voluntad de repetir la visita.

\subsubsection{Impacto del turismo}

El impacto económico del turismo es difícil de calcular, pero algunas cifras ofrecidas por el Ayuntamiento de Valencia (tabla 3), nos permiten señalar que, como en el caso de la oferta de equipamientos de alojamiento y restauración, así como de llegada

1 http://www.camaravalencia.com/es-ES/competitividad/turismo/Documents/Cruceros_agosto2016.pdf 
de turistas y cruceristas, a partir de 2009 se experimenta un ligero retroceso, para a partir de 2014 estabilizarse, con ciertas mejorías (incremento del empleo, sobre todo).

Tabla 3

IMPACTO DEL TURISMO EN LA CIUDAD DE VALENCIA

\begin{tabular}{|c|c|c|c|}
\hline & millones de euros & empleo directo & empleo indirecto \\
\hline 2009 & 1.355 & n.d. & n.d. \\
\hline 2014 & $1.044,9$ & 7.450 & 15.049 \\
\hline 2015 & $1.156,7$ & 8.247 & 16.660 \\
\hline
\end{tabular}

Fuente: Anuario Estadístico Municipal y Turismo Valencia.

Respecto al impacto no económico, cabe indicar que, según el estudio realizado por Marzo et al (2013) para la fundación Turismo Valencia, son siete los factores clave de satisfacción turística en la ciudad: (1) modernidad-exclusividad, (2) transporte-organización de actividades-precio, (3) tranquilidad-espacios verdes, (4) diversión-aprendizaje, (5) gastronomía-comida, (6) tradición e historia y (7) romanticismo; y son cuatro los perfiles emocionales: el vanguardista, el tranquilo, el urbanita organizado y el gastrónomo. En ambos casos, el aspecto relacionado con la modernidad (entendida por los turistas como arquitectura o urbanismo de vanguardia) resulta de gran relevancia para el atractivo turístico. Según este mismo estudio, la CAC es el recurso con mayor atractividad.

\subsection{5. ¿Agotamiento del modelo?}

Los recursos turísticos más demandados han experimentado ciertas variaciones en cuanto a número de visitantes que nos permiten vislumbrar un leve cambio de la tendencia (Gráfica 7). Los recursos vinculados a la arquitectura de escaparate son menos demandados en la actualidad que en 2009 (cuando la imagen de ciudad postmoderna estaba en su máximo esplendor), ganando terreno los recursos patrimoniales más tradicionales y ligados con una cultura e historia diferenciada. Los edificios emblema de la arquitectura vanguardista, como el Museo de las Ciencias y el IVAM pierden visitantes. No así el Oceanogràfic y el Bioparc, que por sus características no son "espacios o contenedores vacíos" sino, bien al contrario, espacios llenos de vida y actividad. También ganan visitantes museos como el de la Beneficencia (Prehistoria, arqueología y etnología), el de Bellas Artes San Pio V y el de Cerámica González Martí, todos ellos con un importante desarrollo de variadas actividades tanto para los residentes como para los turistas.

Entre los edificios que forman la Ciudad de las Artes y las Ciencias, el Oceanogràfic es el más visitado (Gráfica 8). Bien es cierto que la mayoría de los visitantes de la CAC no pueden ser contabilizados porque no compran entrada, sino que disfrutan de la panorámica de este espectacular conjunto de edificios sin interesarse por su contenido. De hecho, la mayoría de las excursiones que ofrecen tanto touroperadores como empresas de guías locales, incluyen la visita "exterior" a la Ciudad de las Artes y las Ciencias, como parte de una ruta que lleva a los turistas por un recorrido que incluye desde la Valencia del siglo de Oro (siglo XVI) hasta la playa y el parque natural de la Albufera. 


\section{Gráfica 7 \\ NÚMERO DE VISITANTES A LOS MUSEOS CON MAYOR AFLUENCIA EN}

LA CIUDAD DE VALENCIA. 2009 Y 2015

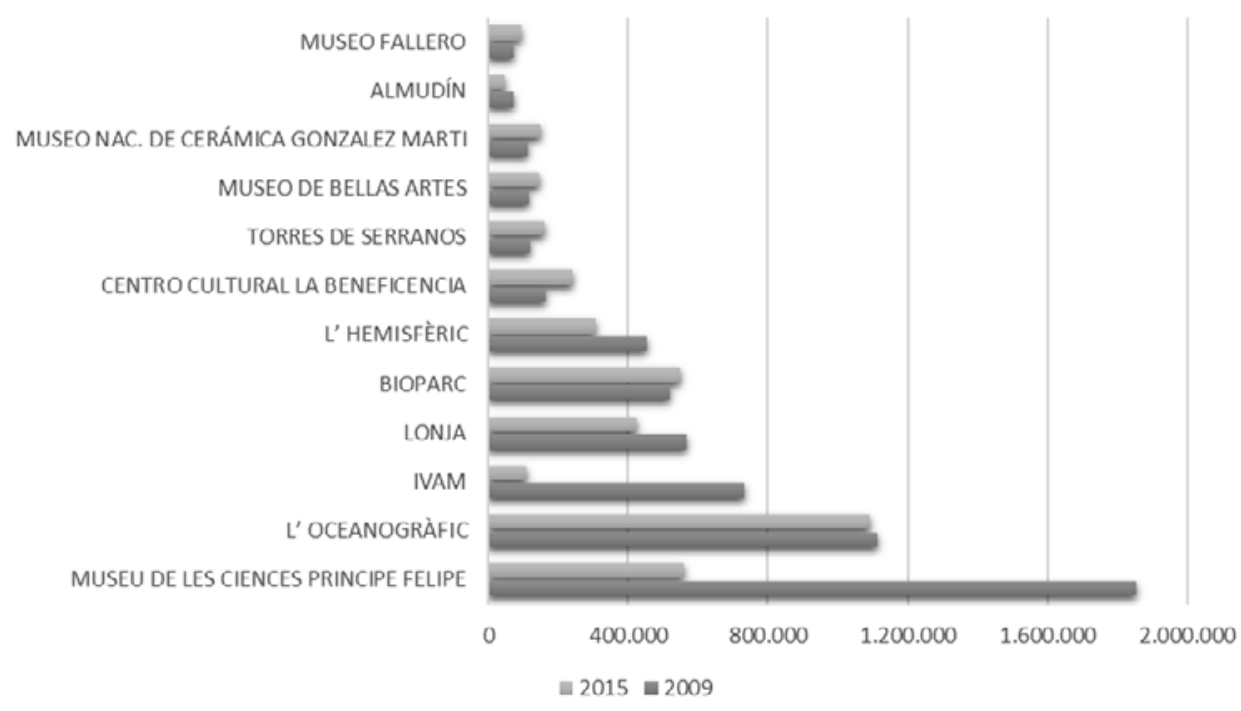

Fuente: Oficina Estadística del Ayuntamiento de Valencia.

\section{Gráfica 8 \\ NÚMERO DE ENTRADAS EN LA CIUDAD DE \\ LAS ARTES Y DE LAS CIENCIAS. 2014-15}

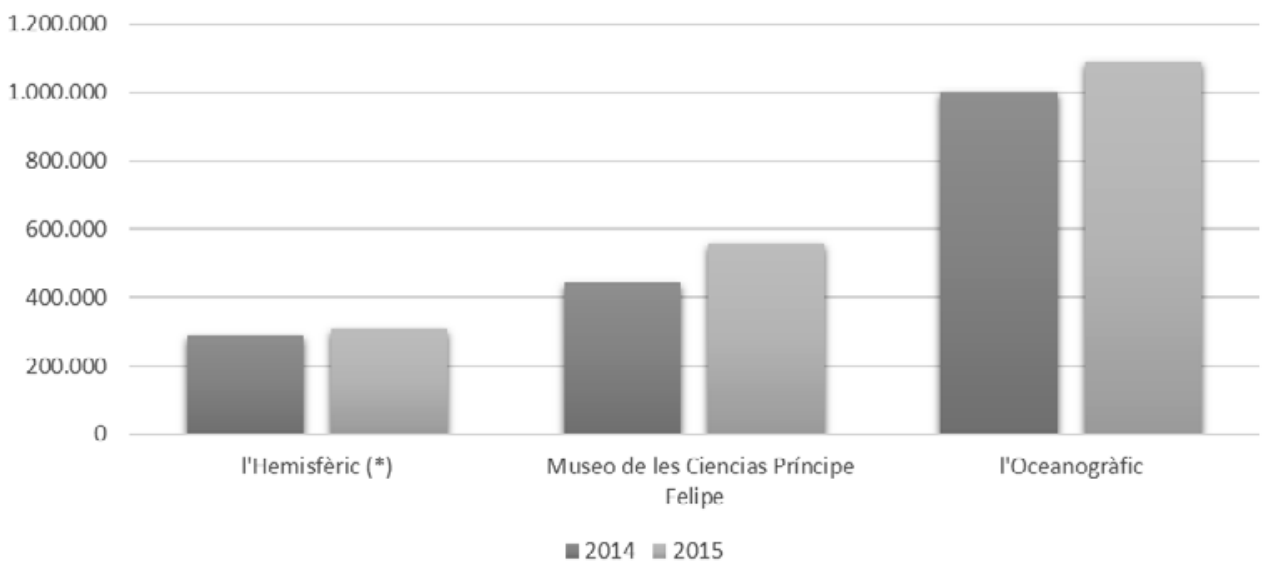

Nota: (*) espectadores.

Fuente: Ciutat de les Arts i de les Ciències. Oficina Estadística del Ayuntamiento de Valencia. 
El origen de los visitantes a cada uno de los edificios de la CAC revela su interés turístico (Gráfica 9). Son mayoría los visitantes de la Comunidad Valenciana en l'Hemisfèric (en comparación con los otros edificios visitables), lo que nos adelanta la idea de que muchos son residentes en la ciudad. Sin embargo, los extranjeros son especialmente importantes en l'Oceanogràfic y en el Museo. Los turistas del resto del Estado son mayoría en los tres edificios, indicando que es en España donde la ciudad de Valencia realmente se ha posicionado y ganado ventaja frente a otras ciudades con una oferta más consolidada.

\section{Gráfica 9 \\ DISTRIBUCIÓN DE LAS ENTRADAS A LA CIUDAD DE LAS ARTES Y DE LAS CIENCIAS, SEGÚN PROCEDENCIA. 2015}

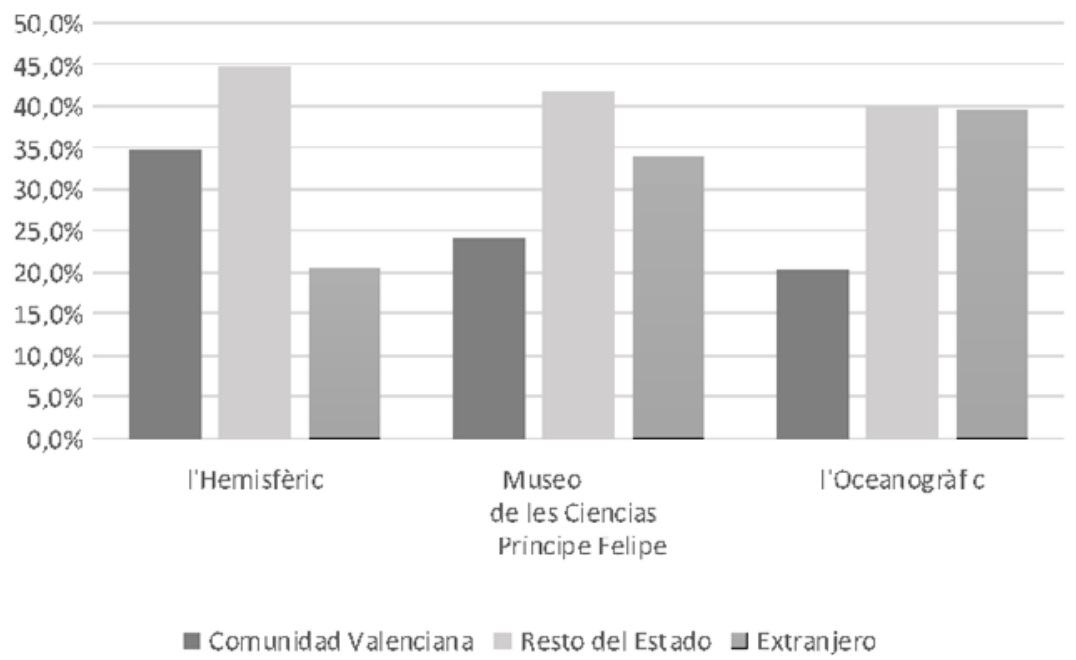

Fuente: Ciutat de les Arts i de les Ciències. Oficina Estadística del Ayuntamiento de Valencia.

Por último, cabe señalar que Valencia es una de las ciudades mejor valoradas de España. Se encontraba en la quinta posición de España en $2012^{2}$, posición que ya ha perdido en 2016. De cualquier forma, los recursos de la ciudad son variados y cubren todas las necesidades. Como ejemplo, según TripAdvisor, entre las cosas que hacer en Valencia ${ }^{3}$, la primera posición (votadas por los viajeros) la ostenta la visita al Mercado Central, la segunda al antiguo cauce del río Turia, la tercera al Bioparc y la cuarta al Oceanogràfic. Valencia es el destino más popular de la Comunidad Valenciana, seguido de Benidorm y de Alicante ${ }^{4}$. En numerosas webs de viajes aparece Valencia como un destino que hay que

2 http://www.lovevalencia.com/valencia-y-benidorm-en-el-top-ten-de-los-mejores-destinos-segun-losturistas.html

3 https:/www.tripadvisor.es/Attractions-g187529-Activities-Valencia_Province_of_Valencia_Valencian_ Country.html

4 https://www.tripadvisor.es/Tourism-g187521-Valencian_Country-Vacations.html 
visitar, muy recomendado y, si obviamos las capitales, aparece como uno de los esenciales para conocer, tanto por su oferta festiva como cultural ${ }^{5}$ y ocupa en 2016 el $9^{\circ}$ puesto entre los destinos emergentes de Europa ${ }^{6}$.

La política de promoción de la ciudad a partir de la organización de grandes eventos es hoy todavía una línea sólida del ayuntamiento. El alcalde actual ha declarado su intención de convertir a Valencia, de nuevo, en sede de acontecimientos internacionales, para lo cual ha puesto en marcha una comisión de proyectos emblemáticos que gestionará y facilitará las inversiones que sean consideradas de interés para la ciudad.

\subsection{Consecuencias de la política de megaproyectos sobre la sociedad local valenciana}

La ciudad de Valencia y su área metropolitana presentan importantes contrastes producto tanto de su historia como de su marcha acelerada hacia la modernidad. La construcción de áreas nuevas con el objetivo de mejorar los centros y espacios obsoletos, la aparición de espacios residenciales de élite junto a barrios tradicionales con problemas propios, y la promoción de complejos comerciales en la periferia urbana, son algunos de los hitos urbanísticos más destacables. Las consecuencias de este proceso se concretan en la pérdida del espacio de huerta alrededor de la ciudad (hoy en proceso de protección como la última huerta mediterránea de España), el aumento de los precios de la vivienda en particular en determinados barrios (los precios en el conjunto de la ciudad han crecido entre 2000 y 2008 más de un 10\% acumulativo anual), la reducción de la vivienda de protección oficial (VPO), que pasó de un 30\% a menos de un $8 \%$ en los años de la burbuja inmobiliaria (Sorribes, 2016), y el desinterés por algunos hitos arquitectónicos que forman parte de la cultura local como el caso del barrio de Cabanyal-Canyamelar (con una arquitectura civil modernista importante, declarada BIC, y en peligro durante años de ser demolido en parte) o la Tabacalera (antigua fábrica de Tabacos dentro de la ciudad que hoy alberga parte de las oficinas del Ayuntamiento, pero que fue en parte demolida).

Como hemos visto, en su transición hacia la era postindustrial, las ciudades han intentado diversificar su actividad productiva y convertirse en centros de servicios -la industria ya no tiene cabida, ni rentabilidad-, en particular destinados a la atracción de turistas con el fin de generar beneficio económico inmediato y, en principio, duradero. Sin embargo, la apuesta por la modernización y la imagen de ciudad global no ha estado exenta de un coste difícil de cuantificar pero evidente por el impacto sobre las personas. En Valencia ha aumentado la pobreza (desde 2013 la presencia de familias en los comedores sociales ha aumentado más de un 60\%) ${ }^{7}$, el desempleo (la ciudad ha perdido 76.500 puestos de trabajo en los últimos 10 años $)^{8}$ y la precariedad laboral entre los grupos más vulnerables

5 http://www.goeuro.es/blog/10-ciudades-no-capitales-esenciales/

6 http://www.20minutos.es/noticia/2625111/0/granada-valencia-lista/destinos-turisticosemergentes/2016-tripadvisor/

7 Informe de Casa de la Caridad de 2017. Ver: http://www.levante-emv.com/valencia/2017/02/15/pobrezacronica-valencia/1529276.html

8 Informe de CC.OO de 2016. Ver: http://valenciaplaza.com/la-ciudad-de-valencia-ha-perdido-76500puestos-de-trabajo-en-los-ultimos-10-anos 
(jóvenes y mujeres) ${ }^{9}$. Todo ello tiene como consecuencia un espacio urbano creado por el racionalismo, el individualismo y la dualización social, elementos que caracterizan a la modernidad líquida de la que hablaba Bauman (2005).

Valencia ha experimentado un cambio sustancial en su imagen internacional, sin duda, sin embargo, la factura total que ha pagado (y sigue pagando) por ello asciende a 886 millones de euros, cifra que abarca la deuda actual de la ciudad. En la Comunidad Valenciana la deuda asciende al $41 \%$ del PIB (más de 43 mil millones de euros), lo cual la sitúa en la cabeza de las comunidades más endeudadas de España (Banco de España, 2016). ${ }^{10}$

Dado que la Generalitat Valenciana ha sido la principal promotora de los megaproyectos, esta estrategia de internacionalización ha supuesto un crecimiento desorbitado de la deuda que hipoteca claramente el desarrollo de los próximos años. Por tener alguna referencia, la Generalitat ha aportado 1.247 millones de euros (el 45\% del gasto) en la Copa América, frente a los 70 millones del Ayuntamiento de Valencia $(2,56 \%)$ o los 289 millones del Gobierno central (8,06\%) (Maudos, 2007).

A pesar del enorme coste de estos proyectos, la percepción de los residentes es contradictoria, pues se valora positivamente la renovación urbanística; sin embargo, como señalan en su estudio Santamaría y Moncusí (2013), cuando se habla de las consecuencias de estas grandes inversiones, "aparece entonces la ciudad de los problemas (paro, inmigración, envejecimiento, etcétera), la que no cumple con las proyecciones o previsiones de generación de riqueza por restitución metonímica o por contagio (VIPs), sino todo lo contrario: la que aumenta desigualdades, la que desplaza a los problemas hacia el futuro o la que, para trazar sus planes de progreso, genera procesos de expulsión orquestados (gentrificación)" (p. 385). La población residente en la ciudad de Valencia considera inviable el endeudamiento presente y futuro, lo que, finalmente lleva a cuestionar el modelo de ciudad existente.

Otras consecuencias de la megalomanía de los gobiernos valencianos hasta la llegada de la crisis económica tienen más que ver con la vida real de los ciudadanos y las familias. Tal es el caso del acceso a la vivienda o a los servicios básicos. Durante los años en los que en Valencia se invertía (y endeudaba) en la construcción de una nueva ciudad, entre 1998 y 2008, el valor catastral de los inmuebles aumentó más de un 65\% (gráfica 10), mientras que la renta familiar disponible se redujo considerablemente (gráfica 11), lo que evidencia una mayor dificultad en la consecución de un derecho básico como es el acceso a la vivienda. Además, una parte importante de los fondos europeos fue gastada en los grandes proyectos urbanísticos y las infraestructuras que sirvieron para darles valor (Monfort, 2010, Gaja, 2016), a costa de no invertirlos en otros equipamientos que pudieran haber sido clave para la mejora de la calidad de vida de algunos barrios. El modelo seguido por Valencia ha buscado el desarrollo económico-empresarial, con dudoso éxito pero importantes consecuencias. Los planes urbanísticos han contribuido a la especulación y al beneficio de unos pocos, sobre todo las empresas constructoras, agudizando los desequilibrios sociales y espaciales.

9 Informe del Ayuntamiento sobre la situación laboral de las mujeres, 2017. Ver: http://www.lavanguardia.com/local/valencia/20170306/42582149269/valencia-constata-en-un-informe-una-mayor-precariedad-en-elempleo-de-mujeres.html

10 Banco de España. Series Estadísticas: http://www.bde.es/webbde/es/estadis/infoest/htmls/cdp.html 


\section{Gráfica 10 \\ VALOR CATASTRAL DE LOS INMUEBLES EN LA CIUDAD DE VALENCIA (MILES DE EUROS)}

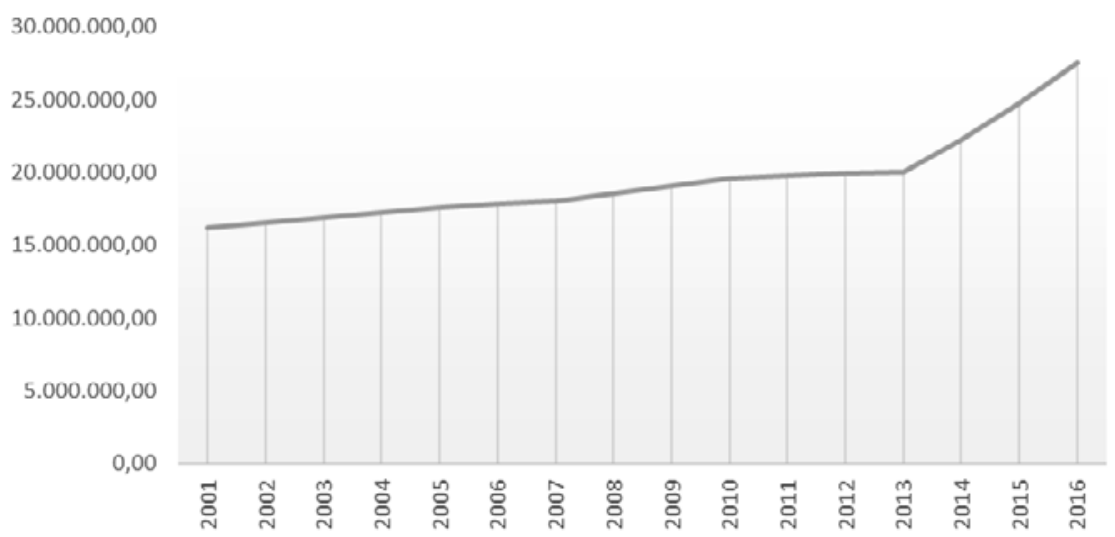

Fuente: Conselleria de Economía Sostenible, Sectores Productivos, Comercio y Trabajo.

\section{Gráfica 11}

INDICADOR DE LA RENTA FAMILIAR DISPONIBLE PER CÁPITA EN LA CIUDAD DE VALENCIA (MILES DE EUROS)

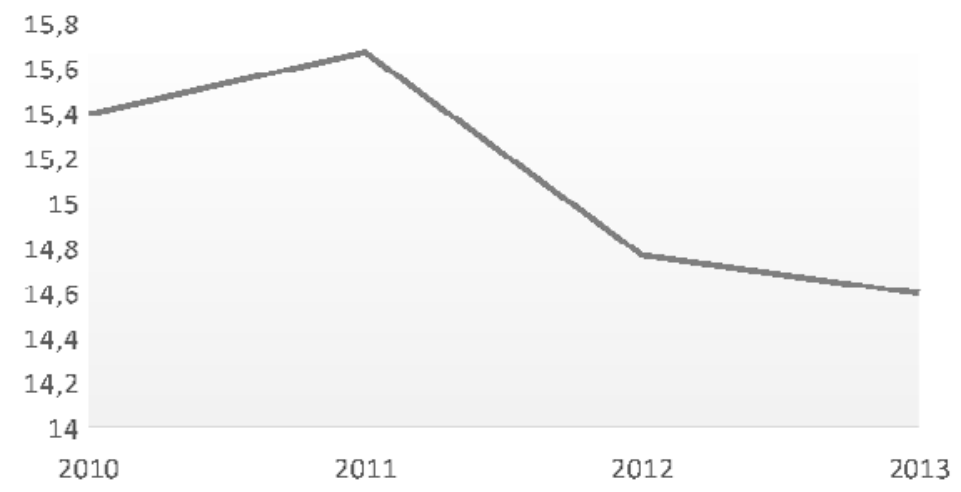

Fuente: Ministerio de Hacienda y Función Pública.

En términos turísticos, la imagen de Valencia asociada a los grandes eventos no es compartida por la sociedad, que, lejos de rechazar el desarrollo turístico, no puede asumir los excesos de las macrointervenciones, ni la corrupción a ellas asociada. La puesta en valor de los recursos asociados a una imagen más auténtica de la realidad valenciana podría haberse realizado con forma más asequible, de acuerdo con la realidad económica local y con la colaboración de los agentes sociales. La especulación urbanística y las exageradas previsiones de llegada de turistas - en particular de gasto elevado- se han saldado con un 
fuerte impacto de la crisis inmobiliaria, el estancamiento en cuanto a construcción de hoteles y la reclasificación a la baja de algunos de ellos, ajustándose poco a poco a la realidad de una demanda. Dicha demanda, además, se consolida a partir de la recuperación de los recursos tradicionales, asociados a la historia y la cultura de la ciudad (el casco histórico, la Albufera, etc.), bien valorados por el turista urbano y, en complementariedad con los macroedificios asociados a la imagen de Valencia, consolidan un producto de gran atractividad que es necesario gestionar de manera integrada (con las políticas urbanas) y sostenible.

La sociedad valenciana, sin embargo, no ha sido indiferente a los excesos inversores en línea con la política urbana neoliberal. Durante los años de bonanza económica se desarrollaron numerosos movimientos ciudadanos en defensa de sus intereses y de los intereses de la ciudad. Se trata de los movimientos "Salvem" que reivindican el espacio urbano y defienden espacios o edificios emblemáticos desde el punto de vista de las necesidades, intereses y afecciones de los residentes (Sorribes, 2016).

En la actualidad, el cambio de gobierno local y regional en las últimas elecciones ha supuesto una paralización y una revisión de los proyectos emprendidos por el anterior consistorio. La prudencia en el gasto y el interés por generar consenso entre los agentes sociales implicados parece la base de la gobernanza local. Recientemente se ha aprobado un plan de Turismo para la ciudad de Valencia (julio de 2017) y está en vías de aprobación la nueva ley de Turismo, Ocio y Hospitalidad de la Comunidad Valenciana que podrían suponer un cambio en la gestión de esta actividad a nivel local y regional.

\section{CONCLUSIONES}

A pesar de la controversia, el impacto de la organización de los grandes eventos deportivos señalados en Valencia, así como de la arquitectura-escaparate, en línea con la New Urban Policy, centrada en la búsqueda de la ciudad competitiva y global, ha sido fundamental para entender la transformación turística que ha experimentado la ciudad desde el comienzo del siglo XXI. No son escasas las críticas, en particular a las consecuencias de esta política de grandes eventos en términos de costes económicos y sociales, pero las cifras exclusivamente turísticas son impactantes. Se pueden, y deben, debatir otras cuestiones, como el modelo turístico de crecimiento sin fin asociado al grave riesgo (ya experimentado) de superación de la capacidad de carga o la necesidad de un crecimiento sostenible a partir de la puesta en valor de otros recursos turísticos más vinculados a la cultura local, pero la realidad es que la ciudad de Valencia ha experimentado un crecimiento en la llegada de turistas y pernoctaciones (sobre todo de extranjeros) que nunca antes había tenido, y ello a pesar de la crisis económica, la escasa capacidad de acogida en los momentos iniciales de este incremento y la competencia de otros destinos con mayor atractividad, aunque no exentos de problemas, como es el caso de Barcelona.

En definitiva, respecto al impacto turístico que una política de megaedificios y de megaeventos ha tenido en la ciudad de Valencia, cabe señalar:

- El crecimiento del número de turistas atraídos por la nueva y vanguardista imagen de la ciudad es evidente; por tanto, se trata de una imagen sólida asociada a turismo urbano (cultura y ocio) 
- El turista es, sobre todo, nacional, pero crece el internacional

- Aumenta ligeramente el gasto medio por turista, lo que compensa las alteraciones que puede haber en cuanto a número total de visitantes

- Las infraestructuras y equipamientos de acogida han evolucionado -y crecido en capacidad- al tiempo que crecía la demanda

- La estacionalidad se va reduciendo (ampliando la temporada)

- La crisis económica no ha tenido un impacto demoledor, en términos de llegada de visitantes, como sí lo han tenido otros sectores económicos

- A partir de 2008 se da una cierta ralentización y/o estancamiento en el número de turistas y en la creación de equipamiento, pero desde 2012 sigue creciendo, aunque a un ritmo más moderado y ajustado a la demanda, que empieza a dar síntomas de saturación.

- En la actualidad, la oferta y la demanda parecen estar llegando a un cierto equilibrio de ajuste, tanto en número como en calidad (número de plazas de hoteles de alta gama ajustándose a la demanda, recursos de gran potencialidad como los relacionados con la cultura tradicional se están poniendo en valor, etc.).

- El turista valora muy bien la ciudad y repetirá la visita. Sin embargo, podría estar percibiendo sólo una parte de la misma, aquella dirigida a dar una imagen internacional asociada a ciertas características que los turistas quieren percibir, lo cual con el tiempo restaría credibilidad al destino y mermaría la confianza en el mismo.

En definitiva, el turismo, en grandes cifras, se ha visto favorecido en Valencia por la política de planificación urbana neoliberal desde finales de los años 90. Sin embargo, más allá de las cifras de turistas y gasto, el análisis de los impactos negativos de este tipo de políticas en la sociedad y la economía local debe servir para reflexionar sobre el modelo turístico más adecuado para una ciudad como Valencia que ya no puede echar marcha atrás ni deshacer los desmanes cometidos. Es necesario, pues, desarrollar herramientas de gestión que ayuden a conseguir una ciudad habitable para todos, residentes $\mathrm{y}$ visitantes.

\section{BIBLIOGRAFÍA}

AMIN, A. y THRIFT, N. (2007): «Cultural-economy and cities», Progress in Human Geography, 31(2), pp. 143-161.

AÑó, V., CALABUIG, F., y PARRA, D. (2012): «Impacto social de un gran evento deportivo: el Gran Premio de Europa de Fórmula 1».CCD.Cultura_Ciencia_Deporte, 7 (19), pp. 53-65.

AÑÓ, V., DUCLOS, D. y PABLOS, C. (2010): «Percepción social del Gran Premio de Europa de Fórmula 1 entre los ciudadanos de Valencia», European Journal of Human Movement, (25), pp. 143-164.

BAUMAN, Z. (2005): Identidad. Madrid: Losada.

BOIRA, J.V. (2010): Valencia. La Ciudad. Valencia: Tirant lo Blanch.

BRENNER, N., PECK, J. y THEODORE, N. (2010): «Variegated neoliberalization: geographies, modalities, pathways», Global networks, 10 (2), pp. 182-222. 
CACER, G. y POITIER, F. (1996): Le tourisme urbain, Paris: Presses Universitaires de France. ESTEBAN, I. (2007): El efecto Guggenheim, del espacio basura al ornamento, Barcelona: Ed. Anagrama.

FERNÁNDEZ ALLES, M.T. (2014): «El impacto turístico de los eventos deportivos: un estudio de caso», Cuadernos de Turismo, $\mathrm{n}^{\circ} 33$, pp. 59-76.

GAGO GARCÍA, C., J. CÓRDOBA ORDÓÑEZ y R. DÍEZ PISONERO (2017): «Los listados de ciudades globales. Desde la práctica investigadora a su utilización como argumento en la planificación urbana neoliberal», Revista Internacional de Sociología 75 (1): e054. doi: http://dx.doi.org/10.3989/ris.2017.75.1.15.11

GAJA I DIAZ, F. (2016): «València, del boom al crac (1979-2007)», en València, 18082015: la història continua... Balandra Edicions, pp.187-205

HARVEY, D. (2012): Revel cities: from the right to the city to the urban revolution. Londres: Verso.

HEREDERO, O. y CHAVES, M.A. (2015): «Las asociaciones «marca producto» y «marca ciudad»», Área Abierta, vol. 5 (2), pp. 63-76.

HERNÁNDEZ, G.M. y Torres, F. (2015): «La hegemonía cultural del glolugar: entre la relegación y la reivindicación local El caso de Valencia», Política y Sociedad, 52(1), pp. 53-73.

MANSVELT, J. (2008): «Geographies of consumption», Progress in Human Geography, 32(1): 105-117. http://dx.doi. org/10.1191/0309132504ph486pr

MARCHENA, M. J. (1998): «Patrimonio y ciudad: nuevos escenarios de promoción y gestión del turismo urbano europeo», en Marchena, M. J. (Ed.), Turismo urbano y patrimonio cultural. Una perspectiva europea, pp. 9-37.

MARZO, R. et al. (2013): «La experiencia turística en la ciudad de Valencia». Revista de biomecánica, Universitat Politècnica de València. Instituto de Biomecánica de Valencia. Vol. 59, pp. 63-66.

MAUDOS, J. (2007): Impacto económico de la $32^{\text {a }}$ Americas Cup Valencia 2007. Informe final IVIE.

McCANELL, D. (2003): El turista. Una nueva teoría de la clase ociosa, Barcelona: Melusina.

MÉNDEZ, R. y SÁNCHEZ, S. (2011): «Spanish cities in the knowledge economy», European Urban and Regional Studies, 18(2), pp. 136-155. http://dx.doi. org/10.1177/0969776410381039

MONFORT MIR, V.M. (2000): «La política turística: una aproximación», Cuadernos de Turismo, $\mathrm{n}^{\circ} 6$, pp. 7-28.

MONFORT MIR, V.M. (2010): «Valencia, turismo cubista», en Sorribes, J. (Ed.), Valencia, 1957-2007, pp. 101-154

MUÑIZ, N. y CERVANTES, M. (2010): «Marketing de ciudades y "Place Branding"», Pecvnia: Revista de la Facultad de Ciencias Económicas y Empresariales, Universidad de León, (2010), pp. 123-149.

OCDE (2009): The impact of Culture on Tourism, Paris: OCDE.

PECK, J. y THEODORE, N. (2015): Fast Policy: Experimental State- craft at the Thresholds of Neoliberalism. Minneapolis: Minnesota Univ. Press. On line: https://muse. jhu .edu/ book/40056 
PLA SIRVENT, D. (2013): «Turismo y política: cómo afectan los grandes eventos al territorio», GeoGraphos: Revista Digital para Estudiantes de Geografía y Ciencias Sociales, ${ }^{\circ} 4$ (36), pp. 93-114.

PUCHE, M. y OBIOL, E. (2011): «Procesos de «re-imageneering» turístico: el eclipse de la identidad local de Valencia», Cuadernos de Turismo, n 28, pp. 191-214.

QUEIROZ y RASTROLLO-HORRILLO (2012): «Cooperación y coordinación entre turismo y cultura: la recreación de la oferta cultural en los «destinos culturales emergentes», en Book of Proceedings - Tourism and Management Studies International Conference Algarve 2012 vol.1, ESGHT-University of El Algarve, Portugal, pp. 109-122.

RAUSELL, P. (2010): «Valencia desde la huerta al ocio». En: SORRIBES, J. (ed.). Valencia, 1957-2007. De la riada a la Copa del América. Valencia: Publicacions de la Universitat de València, pp. 79-100.

RAUSELL, P. y MARCO, F. M. (2005): «Una aproximación al turismo urbano: el valor de la ciudad empaquetada en el caso de Valencia», Revista de Economía, Sociedad, Turismo y Medio Ambiente: RESTMA, vol. 2, pp. 9-34.

RICHARDS, G. (2002): «Tourism attraction systems: Exploring cultural behavior», Annals of tourism research, vol. 29 (4), pp. 1048-1064.

RICHARDS, G. y MUSTERS, W. (2010): Cultural Tourism Research Methods, Wallingford: CAB International.

RITZER, G. (1983): «The "McDonaldization" of society», The Journal of American Culture, vol. 6 (1), pp. 100-107.

RIUS-ULLDEMOLINS, J., HERNÀNDEZ I MARTÍ, G.M. y TORRES, F. (2016): «Urban Development and Cultural Policy "White Elephants": Barcelona and Valencia», European Planning Studies, vol. 24 (1), pp. 61-75.

SAN EUGENIO, J.D. (2013): «La marca de ciudad en la contemporaneidad», Poliartea, vol. 10 (19), pp. 11-27

SAN EUGENIO, J.D. (2014): «Fundamentos conceptuales y teóricos para marcas de territorio», Boletín de la Asociación de Geógrafos Españoles, n 62, pp. 189-211.

SANCHO, A., y GARCÍA, G. (2006): «El impacto de la America’s Cup en la imagen turística de la ciudad de Valencia», en XVI Simposio Internacional de Turismo y Ocio, Barcelona, España. Actas.

SANTAMARÍA, B. (2014): «La Ciudad suplantada. Percepciones sobre los nuevos imaginarios (turísticos) de la ciudad de Valencia», PASOS. Revista de Turismo y Patrimonio Cultural, vol 12 (4), pp. 707-718.

SANTAMARINA, B. y MONCUSÍ, A. (2013): «De huertas y barracas a galaxias faraónicas. Percepciones sociales sobre la mutación de la ciudad de Valencia», Papers: Revista de Sociologia, vol. 98 (2), pp. 365-391.

SANZ, S., y ZHELYAZKOVA, D. (2015): «Situación actual del turismo de cruceros en la ciudad de Valencia», Papers de Turisme, n 56, pp. 81-100.

SERNA, K. y GONZÁLEZ, J. (2016): «Turismo y patrimonio cultural», International Journal of Scientific Managment Tourism, vol. 2 (3), pp. 307-321.

SORRIBES, J. (2016): «Los conflictos en la ciudad de Valencia (1975-2015)», València, 1808-2015: la història continua... Valencia. Balandra Edicions, pp. 563-573. 
URRY, J. (2002): The Tourist Gaze. London: Sage.

VERDÚ, V. (2003): El estilo del mundo: la vida en el capitalismo de ficción (Vol. 300). Barcelona: Anagrama. 